\title{
Estimating Sustainable Timber Production from Tropical Forests
}

\author{
(A Discussion Paper prepared for the World Bank)
}

\author{
Jerome K. Vanclay
}

\begin{abstract}
Summary
Natural forests in the humid tropics differ from temperate and plantation forests in several ways: there may be many tree species; many of these may occur infrequently; there may be a large range of tree sizes and shapes present; tree ages may be unknown and indeterminate; and despite the luxuriant appearance some rainforests, growth rates may be relatively low. This has many implications for timber harvesting and yield estimation and means that most of the estimation techniques devised for even-aged single-species forests cannot be used.

A timber harvest represents the culmination of many years of growth, even in "fast growing" plantations. Thus, unlike the farmer of annual crops, the forest manager must consider the distribution of the harvest over time. Several "rules-of-thumb" for estimating the annual allowable cut are examined, with special emphasis given to the selection of the cutting cycle, to growth and harvesting models, and to inventory and monitoring systems. Strengths and weaknesses of cutting cycle analysis are discussed, and are contrasted with the more sophisticated yield scheduling systems.

Tools, techniques and information sources for estimating timber yields are reviewed. Yield calculations should make full use of existing information, including data from old surveys and casual inspections. Remote sensing and geographic information systems offer several interesting possibilities for yield estimation, particularly for sensitivity testing, but are not without limitations. A check list and extensive references are given.
\end{abstract}

CENTER FOR INTERNATIONAL FORESTRY RESEARCH

office address: JalanGunung Batu 5, Bogor 16001, Indonesia mailing address: P.O. Box 6596 JKPWB, Jakarta 10065, Indonesia tel.: +62 (251)34-3652 fax: +62 (251) 32-6433

email: cifor@cgnet.com 


\section{The CGIAR System}

The Consultative Group on International Agricultural Research (CGIAR) is an informal association of 41 public and private sector donors that supports a network of sixteen international agricultural research institutes, CIFOR being the newest of these. The Group was established in 1971. The CGIAR Centers are part of a global agricultural research system which endeavour to apply international scientific capacity to solution of the problems of the world's disadvantaged people.

\section{CIFOR}

CIFOR was established under the CGIAR system in response to global concerns about the social, environmental and economic consequences of loss and degradation of forests. It operates through a series of highly decentralised partnerships with key institutions and/or individuals throughout the developing and industrialised worlds. The nature and duration of these partnerships are determined by the specific research problems being addressed. This research agenda is under constant review and is subject to change as the partners recognise new opportunities and problems. 


\title{
Estimating Sustainable Timber Production from Tropical Forests
}

\author{
A discussion Paper prepared for the World Bank
}

Jerome K. Vanclay

\begin{abstract}
Summary
Natural forests in the humid tropics differ from temperate and plantation forests in several ways: there may be many tree species; many of these may occur infrequently; there may be a large range of tree sizes and shapes present; tree ages may be unknown and indeterminate; and despite the luxuriant appearance some rainforests, growth rates may be relatively low. This has many implications for timber harvesting and yield estimation and means that most of the estimation techniques devised for even-aged single-species forests cannot be used.

A timber harvest represents the culmination of many years of growth, even in "fast growing" plantations. Thus, unlike the farmer of annual crops, the forest manager must consider the distribution of the harvest over time. Several "rules-of-thumb" for estimating the annual allowable cut are examined, with special emphasis given to the selection of the cutting cycle, to growth and harvesting models, and to inventory and monitoring systems. Strengths and weaknesses of cutting cycle analysis are discussed, and are contrasted with the more sophisticated yield scheduling systems.

Tools, techniques and information sources for estimating timber yields are reviewed. Yield calculations should make full use of existing information, including data from old surveys and casual inspections. Remote sensing and geographic information systems offer several interesting possibilities for yield estimation, particularly for sensitivity testing, but are not without limitations. A check list and extensive references are given.
\end{abstract}

\section{Introduction}

Despite widespread interest in, and general concern for sustainable timber production, many interested parties are ill-equipped to judge if the stated timber harvest for an area is in fact feasible. The purpose of this discussion paper is to offer some insights into how timber yields should be estimated, and to offer some guidelines for critically appraising such estimates. While references for further reading are given, the principal objective is not to teach readers how to prepare estimates, but to give policy makers a basis for appraising estimates and assessing their credibility and limitations.

Yield estimates are an important element of a sustainable forest management system, but simply serve as one of many aspects in planning the harvest. Ultimately, sustainability depends on the conduct of field operations: on planning of operations, training of personnel and quality of supervision. Nonetheless, yield estimates remain an important part of the whole process, and remain necessary to provide the basis for planning and control. In principle, overcutting in the short term may be of little consequence, providing that harvesting standards are maintained and that the forest is allowed adequate time to recover. However, once the whole resource has been cut over, the desire to maintain an uninterrupted harvest may prevent sufficient time for the forest to recover, leading to premature harvesting, changes in the structure and composition of the forest, and in turn, to loss of productivity and biodiversity. Several examples attest to the likelihood of these pressures, and to the degradation that may result from such overcutting. Thus the setting of a realistic allowable annual cut (AAC) is an important, if secondary, component of sustainable forest management.

This paper focuses mainly on natural and seminatural forests in the humid tropics, while temperate and boreal forests are addressed in a companion paper 
(Sollander and Svensson 1996). Although plantations are important in the tropics, they will not be addressed in detail here, since most of the principles of yield estimation remain the same as for temperate plantations, except that the time frame may be much shorter (e.g., tropical pulp wood rotations may be as short as 7 years, compared to sawlog rotations of over 100 years for temperate beech, oak, etc.).

\section{The Nature and Importance of Tropical Forests}

Geographically, the tropics lie between the Tropic of Cancer $\left(23^{\circ} 27^{\prime} \mathrm{N}\right)$ and the Tropic of Capricorn $\left(23^{\circ} 27^{\prime} \mathrm{S}\right)$. In phyto-geographic and ecological terms, it is useful to define the tropics according to climate and vegetation, often by the $20^{\circ} \mathrm{C}$ annual isotherm, approximately $30^{\circ} \mathrm{N}$ and $26^{\circ} \mathrm{S}$. Under this latter definition, the tropics amount to some $47 \%$ of the earth's surface (Lamprecht 1989). And despite the high populations and rapid deforestation in recent years (FAO 1995), the tropical forest still retains about half of the world's species, even though they occupy only seven percent of the land area (Wilson 1988). Currently, about five percent of these forests are reserved as national parks or in similar secure tenure, but these protected forests are unlikely to provide for more than half the forest-dependent species (Williamson 1981); the rest depend upon unprotected lands, lands which will be exploited as production forests, agricultural lands and urban areas. Thus the management of these forests may have a disproportionate effect on the diversity and environmental well-being of the earth.

Natural forests in the humid tropics differ from temperate and plantation forests in several ways:

- there may be many tree species (often more than 100 on a single hectare, and over 1000 in a region);

- many of these may occur infrequently (even common species may only occur once in any given hectare);

- there may be a large range of tree sizes and shapes present (the size distribution may follow a "reverse$\mathrm{J}^{\prime \prime}$ or negative exponential distribution, with trees of every size, with few large and many small trees; trees may also be buttressed, fluted or otherwise "deformed");

- tree ages may be unknown and indeterminate (growth rings, if present, may not be annual rings);

- despite the luxuriant appearance some rainforests, soils may be relatively infertile, with most of the nutrients present in the biomass rather than the mineral soil.
This has many implications for timber harvesting and yield estimation. Although the phytomass may be high, only a small proportion of the total volume may be of commercial interest, became of practical limitations such as size and species characteristics. Because the commercial trees maybe widely dispersed, the area of forest disturbed for a given volume may be much larger than in temperate and plantation forests, despite the large volumes of some individual trees. Buttresses, large branches and decay may mean that only part of each tree bole is merchantable.

Thus, despite appearances, the volume obtained from timber harvesting may not be as high as naive expectations, even in clearfelling operations associated with land-use conversion. Silvicultural and conservation requirements for sustainability may further reduce the volume available in any single harvest. Similarly, despite the bountiful lush appearance of many tropical forests, the nett primary production is less than many expect: commercial timber production in natural forests is usually less than in tropical plantations, and comparable with many temperate mixed-hardwood forests.

The many species and irrelevance of age also mean that most of the estimated techniques devised for evenaged single-species forests cannot be used. Thus this paper will examine several techniques ranging from rules-of-thumb to sophisticated models that may be used by foresters, biometricians and critics to appraise likely timber yields and their sustainability. Although not specifically elaborated upon, many of these concepts also apply to non-timber forest resources (e.g., RosTonen et al. 1995).

\section{Sustainability}

Sustainability has been defined in many ways, but here it suffices to observe that in the broadest sense, it implies the equitable intergenerational sharing of resources, to provide for the needs of today without disadvantaging future generations (e.g., Zwahlen 1995). In the narrower context of timber harvesting, it means that the nominated timber harvest should be maintained in the long term ("perpetuity") without degrading the productive capacity (cf. non-declining even-flow) or other ecological and cultural characteristics of the forest. Although this paper addresses mainly the narrower context of timber harvesting, it also comments on other ecological, economic and social aspects and their implications for timber yields. Note however, that the little emphasis on these aspects in this paper does not imply that they are unimportant. 
Although the term "sustainability" was popularized by the Brundtland report (WCED 1987), the concept has been evident for centuries in European forestry (e.g., Philippe 1346, Evelyn 1664, Carlowitz 1713), and almost certainly existed in many other disciplines and cultures as well. Wiersum (1995) argued that forestry may be "the first science that explicitly incorporated concerns about safeguarding finite natural resources for future generations". The European version of this concept had become established within tropical forestry by the time of (and was probably introduced by) Brandis (1896; also see Negi 1991), a German-trained forester working in Burma with the British Colonial Service, but there is no doubt that many indigenous management systems (but not necessarily all) also embraced some concepts of "wise use" before European contact (e.g., Menzies 1988, Colchester 1994).

A more strict interpretation of the concept became popular in north America during the 1980s (e.g., Parry et al. 1983, Steen 1984), when foresters were obliged to produce a non-declining even-flow of lumber from their forests. However, a non-declining even-flow is neither necessary nor sufficient for sustainability. Nondeclining yields in the medium term do not necessarily ensure sustainability in the long term, since the focus on timber yields may divert attention from other issues. There may also be good commercial reasons to allow the harvest to vary slightly from year to year to accommodate variations in demand. Provided that the running average over several years does not exceed the sustainable harvest, there is no good reason to require that the annual harvest exactly equal the annual allowable cut (AAC) each year. On the contrary, allowing the harvest volume to vary in accordance with demand may do much to help stabilize prices and enhance the economic and social sustainability of the community.

It is difficult to assess the sustainability of a harvest at any point in time. Some simple ratios of successive harvests have been proposed (e.g., sustainable original harvest and sustainable disturbance harvest, see Botkin and Talbot 1992, p.62), but these have several limitations, and do not provide a useful insight into sustainability (Vanclay 1996b). Ultimately, sustainability can be proved only by demonstrating repeated commercial harvesting over a long period, coupled with detailed monitoring and inventory (e.g., Vanclay 1990a). An alternative is to examine the prognosis with simulation studies (e.g., Vanclay 1994a,b). More important than these theoretical simulation studies is the need to maintain the highest standards within practical constraints, to monitor and critically appraise operations, and to improve practices as new opportunities evolve.

\section{Regulating the Harvest}

Most countries, irrespective of their political system, impose regulations on forested lands, in part to ensure that private benefits obtained from harvesting and conversion to other uses are not to the detriment of the general public, now or in the future. These regulations may take the form of permits to harvest or clear, obligations to retain unlogged areas or to regenerate logged areas, controls on the number or capacity of processing plants, or ceilings on the harvest at the local or national level. The setting of an AAC is one way to impose a ceiling on the harvest at the local, provincial or national level. Although much of the literature concerning AACs originates in countries where most of the forest (and most of the log supply) is publicly owned, the concept applies equally well in other situations. Few private concerns would establish a pulp, veneer or sawmill without careful consideration of the supply, stability and security of the raw materials. And even where there are many independent forest owners and wood buyers, the interested parties and the community at large may benefit from a relatively stable harvest planned with the benefit of AAC and other resource estimates. Further discussion of the AAC in this paper refers mainly to a situation dominated by a single large forest owner, but the concepts apply to other situations with few modifications.

A timber harvest represents the culmination of many years of growth, even in "fast growing" plantations. Thus, unlike the farmer of annual crops, the forest manager must consider the distribution of the harvest over time. Like the maker of fine wines and spirits, the annual output (i.e. wine sales or timber harvest) is only a small proportion of the stock (i.e. maturing in the cellar or forest). This analogy offers several useful similarities with forestry:

1. Effective management of the resource (cellar or forest) requires consideration of the current stock, accruals (new vintages or growth of trees and seedlings), and current market potential;

2. The volume of raw materials (grapes, timber, etc.) available depends on the quality demanded and the viable transport distance;

3. Some units (species, variety and site) may reach maturity more quickly than others;

4. General rules-of-thumb may offer a useful guide (e.g., sell a volume equal to that of the new vintage less an allowance for losses such as spoiling and evaporation, cf. mortality; sell a fixed percentage of the stock each year; or sell all stock over a nominal maturity age), but are not absolute and some flexibility may be necessary; 
5. It may be advantageous to increase sales when the market is buoyant, and reduce sales during recessions, providing that the stock is maintained within certain limits;

6. If sales exceed accruals (vintage/growth adjusted for losses) too often, the stock will be compromised, and the viability of the operation may be threatened.

7. Sales can be temporarily increased to manipulate share prices, to the detriment of the unwary investor, but to the benefit of the principals.

Several assumptions (e.g., analogy 2 above) may be critical to AAC estimates. Although it is possible to calculate nett primary production (NPP), the biological equivalent of AAC, this is largely of academic interest, since much is in the form of leaves and twigs of no commercial interest. Estimates of the AAC must take into account species, size, quality and accessibility, and this makes estimates heavily dependent on assumptions. Large changes in AAC may result from changes in demand or technology that make it possible to use additional species, to use smaller logs or logs of inferior quality, to harvest areas on more difficult terrain or with smaller volumes/ha, or to transport logs from further afield. This it is important that such assumptions should be realistic and clearly stated.

\section{Estimating the Sustainable Harvest}

Several "rules-of-thumb" have been proposed for timber harvesting. Some are based on the area of forest, others on growth, and some on expected volume production. Many simple formulae require assumptions which become unsatisfactory in tropical mixed forests, and these will not be reviewed here: see Dwight (1965) or Leuschner (1984 pp. 131-198) for an introduction to several of these formulae. Most of the more satisfactory approaches take explicit account of stand structure, so that the AAC cannot be estimated with a simple formula, but must be calculated via a procedure involving several steps. The first step in several of these methods is to nominate a "cutting cycle", the interval between successive harvests on any particular area. Thus we begin by considering the cutting cycle.

\section{Cutting Cycles}

For a plantation forest, it is comparatively easy to determine the optimum rotation age at which the forest should be felled and replanted (e.g., Leech 1993). A rather simple analysis reveals when the mean volume (or value) of timber produced is maximized; this optimum is increased slightly by a size premium for large logs, and decreased by discounting, by risk (disease, fire), and by tree breeding (more profitable to get better varieties in the ground sooner). However, in natural forests, there are many more factors to take into account, and there may be no simple optimum. Some of the factors to be considered include:

1. silvicultural requirements for the desired species to regenerate after logging;

2 . harvesting infrequently enough to allow an economically viable harvest, and to allow the canopy to recover to maintain ecosystem integrity (e.g., Horne and Gwalter 1982);

3. harvesting frequently enough to maintain nearoptimal density, to minimize losses to mortality, and to avoid damage from excessively heavy harvesting.

The final choice of a cutting cycle is often rather arbitrary. For tropical forests, cutting cycles are typically in the range 20-40 years (Vanclay 1994a).

\section{Area Control}

Area control has its origins in the European concept of a "normal forest", in which the forest is divided into $n$ compartments of equal area, one of each age class (1$\mathrm{n}$ years), the oldest of which is harvested and replanted each year, thus ensuring a uniform flow of timber (assuming no site degrade, etc.). With area control of natural forests managed under a selection system, there may be no clearfell-and-replant, and the cutting cycle indicates the proportion of the area selectively harvested each year (e.g., with a 40-year cycle, $2.5 \%$ of the area may be harvested each year). Clearly, a critical assumption is that all areas are comparable in terms of productivity, accessibility, size structure and species composition. While this assumption may be reasonable for industrial plantations and some temperate forests, it is rarely satisfactory for tropical forests.

A minor variation of area control is a form of volume control where a nominated proportion of the standing volume may be harvested each year. For example, the Queensland Department of Forestry allowed an annual harvest of $1.6 \%$ of the standing volume, based on the assumption that the standing volume should be removed over two successive 30year cutting cycles (Vanclay 1991). Dwight (1965) and Leuschner (1984) reviewed several similar formulae of historic interest. These approaches increase the complexity of yield estimates (since they require 
volume estimates, etc.), but offer few significant advantages over the basic method of area control.

Area control offers some advantages, provided that the selected cutting cycle is realistic. It is comparatively easy to estimate and monitor, and provides some incentive to minimize waste (depending on the royalty system). However, effective monitoring is necessary, as the system offers some temptation to overcut within the allocated area. It also overlooks the fact that compartments may differ substantially in species composition, initial volumes, growth rates, etc. One insidious feature of this weakness is that concessionaires may be tempted to overcut the less productive areas in an attempt to maintain yields, and it is these very areas that typically are the least able to recover from over-exploitation and are the most likely to become degraded by unsympathetic harvesting.

\section{Continuous Forestry Inventory Systems}

One way to avoid many of the questionable assumptions of area control is to measure the growth of the forest directly using a series of plots, and to set the annual harvest equal to the observed growth. Because the plot must be representative of the forest as a whole, it is customary to arrange the permanent plots in a systematic grid (e.g., at intersections of a $1 \mathrm{~km} \mathrm{x} 1 \mathrm{~km}$ grid), so that each plot represents a fixed area of forest (e.g., 100 ha). Such systems of plots have sometimes been called continuous forest inventory (CFI), but harvest regulation is not necessarily the only use to which such plot systems may be put.

When CFI is used for harvest regulation, the following steps are involved:

1. Establish and measure a series of plots on a systematic grid, and compute the initial standing volume in accessible and productive forests $\left(V_{0}=\sum v_{0}\right)$

2. Record the volume of any harvests from these plots $\left(\mathrm{H}_{\mathrm{j}}\right)$

3. Remeasure the plots at regular intervals (e.g., five years) and compute total standing volume of living trees $\left(V_{k}, k=5,10, \ldots\right)$

4. Compute the nett growth (including any harvests):

$$
\Delta V=V_{k}-V_{i}+\Sigma H_{j}, \quad i<j<k
$$

If more than one remeasure is available, it is not clear if the nett growth should be computed using the volume at the initial (i.e. $i=0$ ), most recent measure, or some compromise. These alternatives may provide different estimates reflecting changes in the nature of the resource and in the environment (e.g., rainfall).
One limitation of regulation based on CFI is that it does not recognize that production is dependent on the state of the resource, whereas in practice, timber production depends on species, vigour and stocking (i.e. number of trees per unit area). There may be negligible nett growth in a dense "virgin" (i.e. not previously logged) stand, because any growth may be offset by mortality. Nor will Equation 1 offer the "rest and recuperation" needed by a sparse stand that may result from overcutting, wildfire or wind damage. Thus the CFI "harvest only nett growth" approach should be used only as a guide, moderated by the particular management objectives and silvicultural characteristics of the forest.

Despite these limitations, CFI provides a robust ruleof-thumb for comparing yield estimates, especially in previously unmanaged forests, where silvicultural characteristics are not documented, data are scarce, or experienced staff are unavailable. One bonus of the CFI system is that it can provide a good database for investigating silvicultural and management options, provided that the data are carefully managed and supplemented by experiments involving a range of stand density (Vanclay 1994a).

\section{Cutting Cycle Analysis}

Cutting cycle analysis (CCA) offers a way to estimate the AAC from diverse data, without detailed information on the resource. Unlike area control and CFIbased systems, CCA is predictive, offering insights into the likely nature of future harvests, and allowing some sensitivity testing of options such as cuttingcycle length and intensity of the harvest. The data required for simple CCA are rather basic, and should be available for most managed forests: a nominal cutting cycle, the initial stand table (numbers of trees be species and size classes), and some data on growth and other changes (recruitment and mortality, cf. births and deaths) in the forest.

In its most basic form, CCA takes the average stand table, projects it to the mid-point of the first (or $n$ th) cutting-cycle, simulates a harvest, projects it to the mid-point of the second (or $n+1$ ) cycle, and so on. A very simple example of this calculation is given in Table 1. In this example, several simplifying assumptions are made:

1. only four size classes are used;

2. increment and mortality are assumed to be the same in all size classes (i.e., not related to species or tree size);

3. increment, mortality and recruitment are not affected by stand density; 
4. $25 \%$ of trees in any size class grow into the next class in a 20 -year period;

5. $10 \%$ of trees in each size class die in a 20 -year period;

6. upgrowth from class 1 is replaced by an equivalent number of recruits;

7. harvesting occurs only from class 4 , and removes all of the trees, without damaging and trees in other size classes.

Although all of these assumptions are unsatisfactory in some sense, they are typical of assumptions commonly made in many yield forecasts and AAC calculations. The use of these assumptions is not a recommendation, but merely for demonstration.

The first few rows in Table 1 illustrate how the initial stand table (number of trees per unit area in each size class) is adjusted for anticipated mortality, how the upgrowth is estimated (e.g., for class 3 , survivors at year 20 are predicted as $22.5+11.3-5.6=28.1$, allowing for some rounding off), and how recruits into the smallest class replace upgrowth. Since the exact timing of the harvest may not be known, the CCA simulates the harvest at mid-cycle. Table 1 illustrates a CCA with a 40 -year cutting cycle, so the first harvest is simulated at 20 years. Two more 20-year projections are made (the same procedure is followed, but intermediate steps are not shown) to predict the stand table at the middle of the second cycle and simulate the second and subsequent harvests.

CCA offers per-hectare estimates, so an estimate of the nett productive area is required to derive the AAC from a CCA. Note that the nett productive area may differ substantially from the nominal area zoned for harvesting because of reductions required for inaccessible (physically or legally) and unproductive areas. Care is required in estimating the area involved in stream buffers (e.g., see Vanclay 1994b). Stands with slower growth rates may pose some additional complexity, since harvesting may only be viable every second cycle ("unproductive" is relative).

Although the CCA method has several limitations (even when the 7 simplifying assumptions above are avoided by using more satisfactory alternatives), it is easy to understand, easy to implement (e.g., as a spreadsheet), and easy to explore the implications (e.g., by sensitivity testing). It is obvious that short-term yields depend heavily on the initial stand and the harvesting system (i.e., proportion of trees removed from each size class), and that long-term yields depend entirely on growth rates (including mortality and recruitment). Given assumption 3 above (that increment, mortality and recruitment are not affected by stand density), the simulated harvest will always tend towards a constant value, but in practice, this need not apply. However, in the short-term, harvests depend on initial stand conditions, and may vary considerably (e.g., Table 1). If the intention of the CCA study is to set a "sustainable" AAC, some fine-tuning of the cycle length and harvesting prescription may be necessary to obtain successive harvest estimates that are approximately equal. More sophisticated applications of CCA should address each of the 7 simplifications above, and may involve stratifying the resource and customizing projections for each stratum.

Notice that the name CCA relates to the concept, not to the mechanics, and that the calculation can be done with a few simple constants (as in Table 1), with matrix algebra, or with simulation studies based on dynamic growth models (e.g., Vanclay 1994b). Matrix models have been used extensively by plant demographers, and one great advantage is the compact form in which they can express data. For instance, the calculation presented in Table 1 can be represented as (the derivation of this is given as an appendix):

$$
\left.\left[\begin{array}{ccccc}
1 & 0 & 0 & 0 & 0 \\
.225 & .675 & 0 & 0 & 0 \\
0 & .225 & .675 & 0 & 0 \\
0 & 0 & .225 & .9 & 0 \\
0 & 0 & 0 & 0 & 1
\end{array}\right] \cdot\left[\begin{array}{ccccc}
1 & 0 & 0 & 0 & 0 \\
.225 & .675 & 0 & 0 & 0 \\
0 & .225 & .675 & 0 & 0 \\
0 & 0 & 0 & 0 & 0 \\
0 & 0 & .225 & .9 & 1
\end{array}\right]\right) \cdot\left[\begin{array}{c}
100 \\
50 \\
25 \\
12.5 \\
0
\end{array}\right]
$$

However, despite their efficient ability to condense data, matrix models contribute comparatively little to an understanding of the data, and some model outcomes may result from the method rather than the data (Vanclay 1994a). 
Table 1. Example of cutting cycle analysis assuming that 20 -year upgrowth is $25 \%$ that mortality is $10 \%$ in all classes, that recruitment replaces all upgrowth from the smallest class, and that all the stems in the largest size class are harvested each cycle. See text for discussion and implications.

\begin{tabular}{|c|c|c|c|c|c|c|}
\hline \multirow[t]{2}{*}{ Year } & & \multicolumn{4}{|c|}{ Size class } & \multirow{2}{*}{$\begin{array}{l}\text { Harvest } \\
\text { (stems) }\end{array}$} \\
\hline & & 1 & 2 & 3 & 4 & \\
\hline \multirow[t]{5}{*}{0} & Initial stand & 100 & 50 & 25 & 12.5 & \\
\hline & Deaths & 10 & 5 & 2.5 & 1.3 & \\
\hline & Survivors & 90 & 45 & 22.5 & 11.3 & \\
\hline & Upgrowth to next class & 23 & 11.3 & 5.6 & & \\
\hline & Survivors at year 20 & 68 & 56.3 & 28.1 & 16.9 & \\
\hline \multirow[t]{2}{*}{20} & Recruits & 100 & 56.3 & 28.1 & 16.9 & \\
\hline & Post-harvest & 100 & 56.3 & 28.1 & 0.0 & 16.9 \\
\hline 40 & End cycle 1 & 100 & 60.5 & 31.6 & 6.3 & \\
\hline \multirow[t]{2}{*}{60} & Mid-cycle 2 & 100 & 63.3 & 35.0 & 12.8 & \\
\hline & Post-harvest & 100 & 63.3 & 35.0 & 0.0 & 12.8 \\
\hline 80 & End cycle 2 & 100 & 65.2 & 37.8 & 7.9 & \\
\hline \multirow[t]{2}{*}{100} & Mid-cycle 3 & 100 & 66.5 & 40.2 & 15.6 & \\
\hline & Post-harvest & 100 & 66.5 & 40.2 & 0.0 & 15.6 \\
\hline 120 & End cycle 3 & 100 & 67.4 & 42.1 & 9.1 & \\
\hline \multirow[t]{2}{*}{140} & Mid-cycle 4 & 100 & 68.0 & 43.6 & 17.6 & \\
\hline & Post-harvest & 100 & 68.0 & 43.6 & 0.0 & 17.6 \\
\hline 160 & End cycle 4 & 100 & 68.4 & 44.7 & 9.8 & \\
\hline \multirow[t]{2}{*}{180} & Mid-cycle 5 & 100 & 68.7 & 45.6 & 18.9 & \\
\hline & Post-harvest & 100 & 68.7 & 45.6 & 0.0 & 18.9 \\
\hline 200 & End cycle 5 & 100 & 68.9 & 46.2 & 10.3 & \\
\hline \multirow[t]{2}{*}{220} & Mid-cycle 6 & 100 & 69.0 & 46.7 & 19.6 & \\
\hline & Post-harvest & 100 & 69.0 & 46.7 & 0.0 & 19.6 \\
\hline 240 & End cycle 6 & 100 & 69.1 & 47.0 & 10.5 & \\
\hline \multirow[t]{2}{*}{260} & Mid-cycle 7 & 100 & 69.1 & 47.3 & 20.0 & \\
\hline & Post-harvest & 100 & 69.1 & 47.3 & 0.0 & 20.0 \\
\hline 280 & End cycle 7 & 100 & 69.2 & 47.5 & 10.6 & \\
\hline \multirow[t]{2}{*}{300} & Mid-cycle 8 & 100 & 69.2 & 47.6 & 20.3 & \\
\hline & Post-harvest & 100 & 69.2 & 47.6 & 0.0 & 20.3 \\
\hline 320 & End cycle 8 & 100 & 69.2 & 47.7 & 10.7 & \\
\hline \multirow[t]{2}{*}{340} & Mid-cycle 9 & 100 & 69.2 & 47.8 & 20.4 & \\
\hline & Post-harvest & 100 & 69.2 & 47.8 & 0.0 & 20.4 \\
\hline 360 & End cycle 9 & 100 & 69.2 & 47.8 & 10.7 & \\
\hline \multirow[t]{2}{*}{380} & Mid-cycle 10 & 100 & 69.2 & 47.8 & 20.4 & \\
\hline & Post-harvest & 100 & 69.2 & 47.8 & 0.0 & 20.4 \\
\hline 400 & End cycle 10 & 100 & 69.2 & 47.9 & 10.8 & \\
\hline
\end{tabular}


At its best, CCA overcomes many of the limitations of area control and CFI-based regulation, but it does demand reliable data on areas, initial stands, and on growth (including recruitment and mortality). However, as commonly applied, it implicitly assumes a moratorium on harvesting for one-half cycle, and in managed forests this may lead to significant bias in estimates. In many studies, subjective estimates of growth are used in place of reliable data (e.g., $1 \mathrm{~cm}$ diameter increment and 1\% mortality per year have been assumed in some studies), and such estimates are usually overly optimistic, and may exacerbate the bias.

\section{Yield Scheduling}

Yield scheduling (in the broad sense, encompassing both heuristic and mathematical programming methods) attempts to overcome the limitations of the above methods, by simulating both the growth on each individual forest unit, and the anticipated sequence of harvesting these units. It demands considerably more sophistication than the alternatives, but seems to offer the "best" (most accurate, and most easily checked) yield forecasts, the most reliable indicators of sustainability, and the greatest utility at the management level. Yield schedules can be determined using heuristic simulation or mathematical programming, but the former seems to offer advantages in many native forest contexts (Vanclay 1991, 1994a). Heuristic simulations are rule-based, iterative trial-and-error approximations which converge to a good solution, but may be the most efficient way to arrive at a near-optimal harvest schedule, especially in complex natural forests where the number of options may make mathematical programming impractical.

Yield scheduling typically involves stratifying the resource into management units and homogeneous subunits, sampling each subunit, nominating a target AAC, setting $t=0$ and then repeating the following steps until the resource is exhausted or $t$ is sufficiently large:

1. estimating harvestable volumes within each management unit at time $t$;

2. selecting the management unit which best meets specified criteria (highest volume, longest time since last harvest, close but not adjacent to previous harvested unit, serviced by same road, etc.; see e.g., Vanclay 1994a) and simulating the harvest on those subunits which satisfy criteria specified at the subunit-level (e.g., yields/ha);

3. calculating the time to harvest the unit and updating all stand tables by estimating growth during this period (set $t=t+$ yield/AAC).
Note that no cutting cycle is assumed, and that the frequency of harvesting may vary from unit to unit according to species composition and productivity. Despite the additional complexity compared to CCA, yield scheduling is worth pursuing, since it not only offers reliable estimates of the AAC, but also provides much useful information for operational management of a forest estate, including detailed harvest schedules, harvest estimates broken down by species and size, and information concerning the nature of the residual forest (e.g., Vanclay 1994b). One of the great strengths of yield scheduling is that yield predictions are made for each management unit, enabling efficient checking of predictions and offering an early-warning system for many errors.

Although yield scheduling may offer the most reliable estimates of AAC, it is not necessarily a panacea. It is important that users understand the method and the calculation, understand the limitations of their data, and fully comprehend the resulting AAC estimates. A disadvantage of yield scheduling is that the computer skills and resources required may cause it to be viewed as a "black box" accessible only to an organization's "computer-wizard", rather than as a tool to be more widely used. This may be a serious disadvantage if it becomes the basis for power-games and empirebuilding. Under such circumstances, the simplicity and transparency of a simple cutting cycle analysis on a spreadsheet may be a significant advantage.

Clearly, there is no single "best" system for estimating AACs: the quality of estimates always depends on the quality of the data and the nature of the assumptions. The appropriate approach depends on the data, resources and skills available. Organizations should commence with something simple, understandable and achievable, and aim to progress to more sophisticated methods as skills develop and data and resources come to hand.

\section{Techniques and Tools for Yield Estimation}

Below is a brief overview of a variety of tools, techniques and information sources that may facilitate the estimation of timber yields for natural forests. The basic prerequisites are summaries of the nature, extent and growth of the present forest estate. These data may be obtained from various sources, not necessarily at a single point in time. Although the quality of these inputs will obviously determine the reliability of the AAC estimate, the absence of "perfect" data should not become an excuse for inaction: no data are perfect, 
and any estimate of the AAC can be helpful for planning, provided that limitations are known.

\section{Resource Inventory}

The first prerequisite for estimating the $\mathrm{AAC}$ is resource inventory describing the nature and extent of the forest resource. National forest inventories (or equivalently, estate-wide inventories in the case of a non-government agency) provide a convenient basis for AAC estimation, but they are not the only source of such data, and are not necessarily the most efficient way to obtain the necessary details. An on-going inventory programme can provide equivalent data while avoiding many of the logistical, financial and integrity problems associated with the one-off approaches usually adopted for national forest inventories. Rolling inventory programmes also offer greater opportunities to customize procedures to accommodate operational, management and planning needs (e.g., yield scheduling needs), and to integrate inventory with other field work to increase efficiency. Some careful thought about the real needs and end-uses of inventory data, before commencing any fieldwork, pays dividends.

AACs can be estimated from many kinds of data, but the minimum requirement is to stratify the resource according to productivity and management intention, and sample each stratum to gain an estimate of:

- nett productive area and

- species and sizes of commercial trees (e.g. over 20 cm diameter)

within each stratum. This represents the absolute minimum requirement, and it is preferable that resource inventory should sample trees of all species. Ideally, all trees over $10 \mathrm{~cm}$ diameter should be sampled, measured to the nearest $1 \mathrm{~cm}$, and recorded as separate entities (i.e., not aggregated into a stand table). Standard texts on forest inventory should be consulted for further guidance.

\section{Prior Information for Stratification}

Stratification is one of the most efficient ways to reduce the variance associated with a resource estimate, and AAC estimates are no exception. Strata may be defined on the basis of forest type, site quality, management history, and other existing information, especially from formal and informal inventory and maps. Many aspects of managed forests are largely invariant (e.g., forest type, species composition, site quality, slope, accessibility, etc.) or slow to change (e.g., stand tables, tree sizes, standing volumes, etc.), so that much informa- tion pertaining to forests remains fairly durable over relatively long time-frames. This is fortunate, as forest inventory is expensive, and it behooves resource managers to consider carefully all existing information, and make full use of any data that remain pertinent.

Today, it is rare to find that no prior information exists for a forest, since old surveys, maps and aerial photos can all be used to improve resource estimates. Effective stratification may be one of the most important steps in preparing a resource estimate or AAC, and old survey data (field notes, sketch maps and plot measurements), maps, aerial photos and remote sensing data (digital or imagery) may all be helpful in documenting logging (or land use) history, in forming logical management units, and in defining relatively homogeneous strata. Old plot data may be used to supplement current sampling, especially if the area has not been logged or otherwise disturbed in a significant way.

\section{Rapid Appraisals}

Rapid appraisals of various kinds (including rapid rural appraisals and participatory rural appraisals) have commanded considerable attention in recent years, especially in the social sciences (see e.g., Grandstaff and Messerschmidt 1995, Mikkelsen 1995), but there have been few reports of the use of these methods in estimating timber resources. Although there are some problems with the use of subjective data, it is both expedient and efficient to employ local knowledge of all kinds in preparing resource estimates. Local knowledge may be useful in stratifying the resource, in assigning growth rates to species for which there are no empirical data, and in schemes to extrapolate existing inventory data.

Sufficient reliable resource inventory is critical to the quality of resource estimates, but is expensive to obtain. Travel costs contribute a substantial proportion of total inventory costs, and one way to reduce the cost of inventory is to obtain these data during other routine operations and inspections. Point-based inventory using optical wedges can be fast, efficient and easy to complete with a team as small as two persons. A good inventory system should alert staff of management units in need of further sampling (e.g., units with incomplete or out-dated samples, or with high variances), so that additional inventory may be done when convenient and efficient. There are some limitations to the use of such opportunistic data, but provided that it supplements more formal sampling systems, and that no plots are subjectively discarded as "unrepresentative", such sampling schemes may provide a cost-effective way to enhance resource estimates (Vanclay 1994b). 


\section{Remote Sensing}

Remotely sensed data are now readily available for all forests, both in digital and photographic form, and may offer a good insight into the distribution, variability and general nature of the timber-bearing portion of a forest. The most widely available and most widely used forms of remotely-sensed data include aerial and satellite imagery (monochrome, colour and infra-red photographs, and images created from digital sources). There is no doubt that these media have been, and will remain an important source of spatial information for forest management, despite the many problems with clouds in the tropics. With images reconstructed from digital sources, users may have a choice of wavelengths (e.g., with Landsat MSS and TM, but also with airborne scanners), and combinations such as red, near-infrared, and mid-infra-red have shown great promise in revealing details of silvicultural interest while minimizing the effects of haze and other forms of atmospheric distortion. The emerging radar-based technologies offer great promise with their cloud-penetrating ability (e.g., see Nezry et al. 1993, Thompson et al. 1993, Hoekman et al. 1995), but these are yet to be proven for operational use.

Digital data sources can be analyzed by computer rather than by manual interpretation, and this offers both opportunities and problems. Several computer packages are now available for such analyses, and greatly simplify the task, making it easy to produce impressive-looking outputs. Users are cautioned not to blindly accept such analyses, but to conduct careful ground-truthing, and to compile formal confusion matrices to test the quality of interpretations; such comparisons may be very revealing.

Remotely-sensed data, especially when in digital form, can be used not only to identify forest types and land use, but also to infer various details about the forest, including stand density and site quality. Landsat thematic mapper (TM) bands 3, 4 and 5 (red, near infra-red and mid-infra-red) have been shown to be useful in this regard (e.g., Sader et al. 1990, Vanclay and Preston 1990), but the technology is changing rapidly, and it is appropriate to explore any new developments, especially the currently emerging radar technologies.

\section{GIS and Area Estimates}

Area estimates are a critical component of most AAC estimates, and efficient and repeatable methods for estimating forest areas in various land categories are needed. The importance of reliable area estimates cannot be overstated, as nett area estimates are one of the major factors contributing to conflicting yield estimates (Vanclay 1996).

Geographic information systems (GIS) offer several advantages, and are becoming widely used in this capacity (e.g., Wood and Turner 1992, Sample 1994), but they are expensive and non-essential. One of the hidden costs often not fully appreciated is the high cost of data capture. The purchase of the hardware and software necessary to implement a GIS typically represents less than one tenth of the total cost, the major component being the cost of data collection and checking. Vector-based GIS systems (such as the ESRI Arc/Info system, cf. raster-based systems) may be particularly expensive in this regard, as care must be taken that each polygon is correctly closed and linked to the attribute file. However, these systems also offer powerful advantages, such as the ability to explore the potential impacts of management options (e.g., consequences for timber yields of changing stream buffers, slope restrictions, etc.) and the ability to prepare presentation-standard maps and other graphics.

Reliable resource estimates cannot be prepared for any substantial area without an efficient database of land attributes, but this need not take the form of a vector-based GIS. One efficient alternative is to keep the expensive line-work on paper as maps (not necessarily as multi-coloured A0 sheets; black-and-white line work on A4 sheets housed in a filing cabinet may be more efficient), to assign each management unit (and subunit) a unique identifier, and to maintain a simple computerized database (e.g., in a DBase-type package) of all attributes corresponding to each unit. This approach has been, and continues to be used in the Queensland Forest Service for all but the most politically-sensitive forest areas (Vanclay 1990b).

\section{Growth Models and Permanent Sample Plots}

Growth models have become an indispensable part of yield prediction systems, offering greater accuracy, more detail, and more flexibility than earlier formulabased methods or regulating harvests. One particular attraction of dynamic growth models is the ability to conduct sensitivity analyses and explore implications of management alternatives, which should, if used wisely, lead to a better understanding of the model, of the ecosystem, and in turn, to better management.

Hundreds, and possibly thousands of growth models have been published, and although relatively few of these relate to tropical forests, this is not the place to 

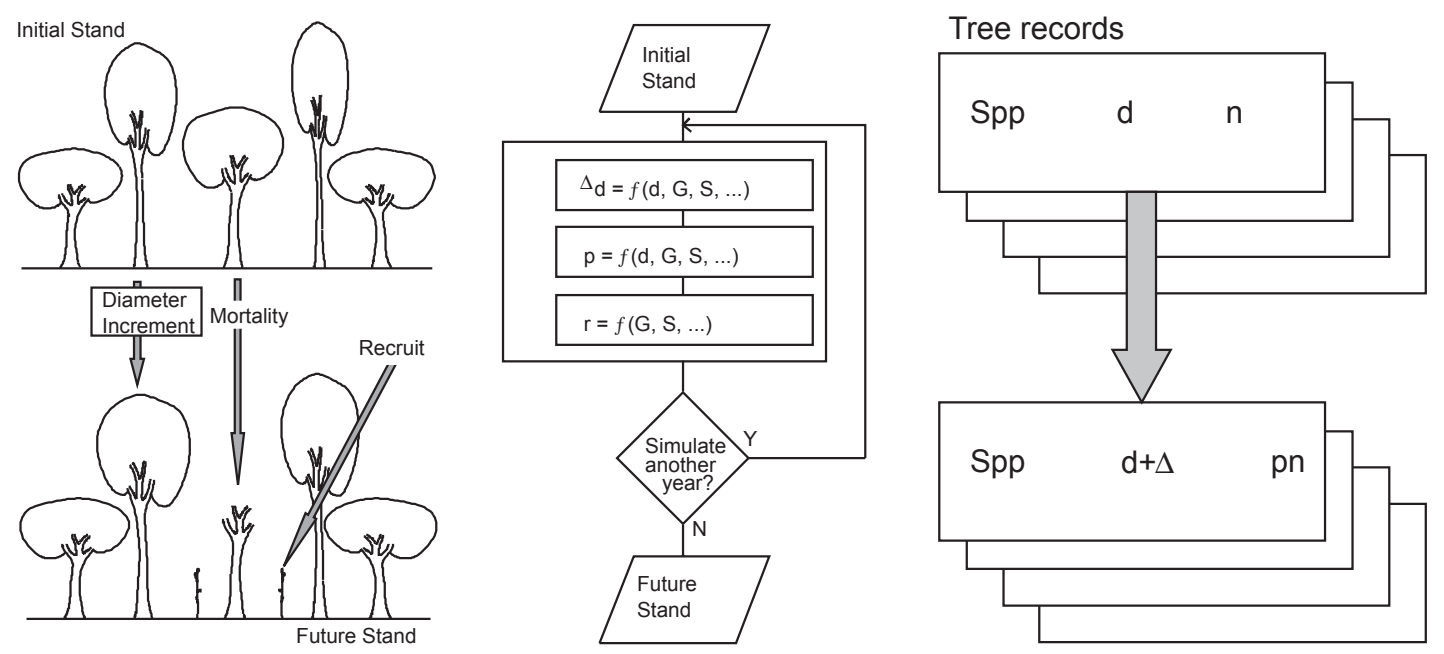

Figure 1. Illustration of tree-list approach to growth modelling (adapted from Vanclay 1994a). Each tree recorded on a plot is represented by a tree-record, characterized by its species which remains unchanged, its size which is increased to account for growth, and its frequency (stems/hectare represented) which is reduced to account for mortality.

attempt a review (see Vanclay 1995a), or an explanation of all the steps and considerations involved. Perhaps it suffices to say here that models may be more-or-less theoretically or empirically based, and may make predictions at the whole-stand, size-class or individual-tree level. Although there is a place for all such models, the empirical individual-tree models presently seem to offer the greatest utility for forest management and operational yield forecasting in mixed tropical forests. The construction of such models is not something that can be automated or completed according to a prescription, but involves both science and imagination to craft sensible relationships and construct critical tests of model performance (Vanclay 1994a).

Many growth models for tropical forests rely on simple stand table projection (Table 1) or transition matrices (Appendix), but the more detailed and reliable models usually follow the tree-list approach (Figure 1). This formulation represents actual plot data in the computer as a list of tree-records, each of which has a species, size and frequency. During each year simulated, each tree-record is updated by leaving the species unchanged, increasing the size to account for growth, and reducing the frequency to account for mortality. Additional tree-records may be added from time-to-time to account for regeneration and recruitment. The predicted growth and mortality rates may be speciesspecific, and usually rely on empirical data.

The quality of a growth model depends heavily on the quality of the data used to calibrate and test the model, and since tropical trees are rarely amenable to stem analysis (i.e., growth rings may not be visible or may not be annual), data from remeasured permanent sample plots are required. There is no short-cut way to get these data; plots need to be established and remeasured regularly over long periods. Several publications give detailed instructions and sound advice for the establishment and maintenance of plots (e.g., Alder and Synnott 1992, Beetson et al. 1992, Sheil 1995, Whitmore 1989).

If no growth data are available locally, it may be possible to obtain suitable growth estimates from the literature, or to locate suitable sources of comparable data via systems such as TROPIS (Vanclay 1995b).

\section{Simulation and Optimization Systems}

A growth models is of limited use as a stand-alone package, and maximum benefit can only be gained if it is linked with an interactive simulation system which enables users to examine options, explore implications and thus discover optimal silvics for any given situation. Few such systems exist, perhaps because this task is usually left to modellers, even though their interests and 
skills may not be well suited to this task. Vanclay (1990b) discussed some desirable attributes of such systems, and Bossel (1994) offered an example of a good MicrosoftWindows-based user interface for a model.

Optimization systems have received more attention, and several studies have attempted to define optimal stand structures and management systems for specified objectives. However, outcomes seem to depend heavily on the specified objective, on assumptions made, and on the model used; one study reported that optimizing was a good way to detect errors in a model. Although optimization studies may serve as a useful adjunct to other management guides, they should be interpreted with caution.

\section{Monitoring}

It is difficult to appraise the quality of a growth model and yield prediction system (Vanclay and Skovsgaard 1996), and the variance of predictions may be larger than many users may appreciate (e.g., Gertner et al. 1995). One advantage of yield scheduling is that it provides location-specific predictions that can be checked against actual harvests. Users should not expect the prediction for any single management unit to be correct, but the average discrepancy between predicted and observed yields for a succession of several management units should be small. Any large discrepancies should be investigated, by systematically re-evaluating the basic components of the estimate: area estimates, inventory data, growth and harvesting models, and volume equations. It is more difficult to monitor the quality of predictions when the AAC has been estimated by other methods such as CCA, but forest managers should be aware of the need to monitor and periodically re-appraise the relevance of AAC estimates.

\section{Checklist}

Perhaps the most useful synthesis of a document like this is a checklist of items to consider when appraising an AAC calculation. The following aspects should be addressed:

1. Are area estimates reasonable?

2. Have due allowances been made for inaccessible and unproductive areas?

3 . Is the stratification reasonable?

4. Are growth estimates realistic?

5. Has due allowance been made for mortality and deterioration of merchantable stems?

6. Is the harvesting model consistent with field practice?

7. Has due allowance been made for breakage and defect?

8. Has due allowance been made for damage to the residual stand?

9. Are the volume equations reliable?

10. Do they allow for defect?

11. Are the cutting cycle and the timing of harvests realistic?

12. Are all assumptions clearly stated?

13. Finally, is the AAC being applied in a way which will achieve the desired objectives, rather than as a blanket rule which may cause instability in prices and communities?

I apologize to readers for the repeated use of "reasonable" and "realistic" in this checklist, but it seems unavoidable. I trust that the text clarifies these issues somewhat, and suggest that an expert be consulted if any doubt remains. 


\section{References}

Alder, D. and Synnott, T.J., 1992. Permanent sample plot techniques for mixed tropical forest. Oxford Forestry Institute, Tropical Forestry Papers 25.

Beetson, T., Nester, M. and Vanclay, J.K., 1992. Enhancing a permanent sample plot system in natural forests. The Statistician 41:525-538.

Bossel, H., 1994. TREEDYN3 - Forest Simulation Model. Forschungszentrum Wald-oekosysteme der Universitaet Goettingen, Germany, Report B 35 (ISSN 0939-1339).

Botkin, D.B. and Talbot, L.M., 1992. Biological diversity and forests. In N.P. Sharma (ed.) Managing the World's Forests: Looking for balance between conservation and development. Kendall/Hunt, Dubuque, Iowa, pp. 47-74.

Brandis, D., 1896. The Burma teak forests. Garden and Forest. Reprinted 1990, The Burma selection system, Asia Pacific Forest Industries 124:13-21.

Carlowitz, H.C. von, 1713. Sylvicultura oeconomica, oder, Hausswirthliche Nachricht und naturmassige Anweisung zur wilden Baumzucht.

Colchester, M., 1994. Sustaining the forests: the community-based approach in south and south-east Asia. Development and Change 25:69-100.

Dwight, T.W., 1965. Confusion worse confounded: the sad story of forest regulation. Forest Chronicle 41:76-83.

Evelyn, J. 1664. Sylva, or a discourse on forest trees.

FAO (Food and Agriculture Organization of the United Nations), 1995. Forest resources assessment 1990: Global synthesis. FAO Forestry Paper 124.

Gertner, G.Z., Cao, X. and Zhu, H., 1995. A quality assessment of a Weibull based growth projection system. Forest Ecology and Management 71:235-250.

Grandstaff, T.B. and Messerschmidt, D.A., 1995. A manager's guide to the use of rapid rural appraisal. Farmercentred Agricultural Resource Management Programme, FAO, Bangkok. FARM Field Document No. 1.

Hoekman, D.H., van der Sanden, J.J. and Bijker, W., 1995. Radar remote sensing of tropical rain forests: the AirSAR-93 campaign in Guyana and Colombia. Final report of BCRS project 3.3/AO-06 entitled AirSAR'93 Tropical Rainforests, December 1995, Wageningen Agricultural University, 59 pp.

Horne, R. and Gwalter, J.,1982. The recovery of rainforest overstorey following logging. I. Subtropical rainforest. Australian Forest Research 13:29-44.

Lamprecht, H.,1989. Silviculture in the Tropics. GTZ, Eschborn.

Leuschner, W.A., 1984. Introduction to Forest Resource Management. Wiley, NY. Reprinted 1992 by Krieger, Malabar.

Menzies, N., 1988. Three hundred years of taungya: a sustainable system of forestry in south China. Human Ecology 16:361-376.

Mikkelsen, B., 1995. Methods for Development Work and Research: A guide for practitioners. Sage, New Delhi. 
Negi, S.S., 1991. Sir Dietrich Brandis: Father of tropical forestry. Bishen Singh Mahendra Pal Singh, Dehra Dun.

Nezry, E., Mougin, E., Lopes, A., Gastellu-Etchegorry, J.P. and Laumonier, Y., 1993. Tropical vegetation mapping with combined visible and SAR spaceborne data. International Journal of Remote Sensing 14:2165-2184.

Parry, B.T., Vaux, H.J. and Dennis, N., 1983. Changing conceptions of sustained-yield policy on the national forests. Journal of Forestry 81:150-154.

Philippe VI de Valois, 1346. Ordonnance de Brunoy, article IV. May 1346.

Ros-Tonen, M., Dijkman W. and Lammerts van Bueren, E., 1995. Commercial and sustainable extraction of nontimber forest products: towards a policy and management oriented research strategy. Tropenbos, Wageningen.

Sader, S.A., Stone, T.A. and Joyce, A.T., 1990. Remote sensing of tropical forests: an overview of research and applications using non-photographic sensors. Photogrammetric Engineering and Remote Sensing 56: 13451351.

Sample V.A. (ed.), 1994. Remote sensing and GIS in ecosystem management. Island Press, Washington DC.

Sheil, D., 1995. A critique of permanent plot methods and analysis with examples from Budongo forest, Uganda. Forest Ecology and Management 77:11-34.

Sollander, E. and Svensson, S.A., 1996. Sustainable forest management and determination of sustainable harvesting levels. National Board of Forestry, Sweden, Manuscript 1996-03-01, 36 pp.

Steen, H.K. (ed.), 1984. History of sustained-yield forestry: a symposium. Forest History Society.

Thompson, MD., Macdonald, B.C. and Jefferies, W.C., 1993. Progress in forest mapping using airborne radar in tropical regions. ITC-Journal 4:347-354.

Vanclay, J.K., 1990a. Effects of selection logging on rainforest productivity. Australian Forestry 53:200-214.

Vanclay, J.K., 1990b. Design and implementation of a state-of-the-art inventory and forecasting system for indigenous forests. In H.G. Lund and G. Preto (eds) Global Natural Resource Monitoring and Assessment: Preparing for the 21st century, Proceedings of the international conference and workshop, Sept 24-30, 1989, Venice, Italy. American Society for Photogrammetry and Remote Sensing, Bethesda, USA, pp. 1072-1078

Vanclay, J.K., 1991. Modelling the growth and yield of tropical forests. D. Sc. For. Thesis, University of Queensland, Brisbane.

Vanclay, J.K., 1993. Lessons from the Queensland rainforest: A century striving for sustainability. In P.J. Wood, J.K. Vanclay and Wan Razali Wan Mohd (eds) The Quest for Sustainability: 100 years of silviculture and management in the tropics. Proceedings of Tropical Silviculture Workshop, IUFRO Centennial conference, Berlin, 1-3 September, 1992. FRIM, Kuala Lumpur, pp. 69-89.

Vanclay, J.K., 1994a. Modelling Forest Growth and Yield: Applications to Mixed Tropical Forests. Centre for Agriculture and Biosciences International, Wallingford, U.K.

Vanclay, J.K., 1994b. Sustainable timber harvesting: Simulation studies in the tropical rainforests of north Queensland. Forest Ecology and Management 69:299-320.

Vanclay, J.K., 1995a. Growth models for tropical forests: a synthesis of models and methods. Forest Science 41:742.

Vanclay, J.K., 1995b. TROPIS workshop, Bogor, 4-8 December 1995. CIFOR News 9:6. 
Vanclay, J.K., 1996a. Lessons from the Queensland rainforests: Steps towards sustainability. Journal of Sustainable Forestry 3(2/3):1-17.

Vanclay, J.K., 1996b. Assessing the sustainability of timber harvests from natural forests: Limitations of indices based on successive harvests. Journal of Sustainable Forestry, in press.

Vanclay, J.K. and Skovsgaard, J.P., 1996. Evaluating Forest Growth Models. Ecological Modelling, in press.

Vanclay, J.K. and Preston, R.A., 1990. Utility of Landsat Thematic data for mapping site productivity in tropical moist forests. Photogrammetric Engineering and Remote Sensing 56:1383-1388.

WCED (World Commission on Environment and Development), 1987. Our Common Future. Oxford University Press, London.

Whitmore, T.C., 1989. Guidelines to avoid remeasurement problems in permanent sample plots in tropical rain forests. Biotropica 21:282-283.

Wiersum, K.F., 200 years of sustainability in forestry: lessons from history. Environmental Management 19:321329.

Williamson, M.H., 1981. Island Populations. Oxford University Press, Oxford.

Wilson, E.O., 1988. The current state of biological diversity. P.3-18 in E.O. Wilson and F.M. Peter (eds) Biodiversity. National Academy Press, Washington D.C.

Wood, G.B. and Turner, B.J. (eds), 1992. Integrating forest information over space and time. Proceedings of the IUFRO Conference, 13-17 January 1992, Canberra, Australia. ANUTECH, Canberra.

Zwahlen, R., 1995. The sustainability of resources versus the sustainability of use: a comment. International Journal of Sustainable Development and World Ecology 2:294-296. 


\section{Appendix: AAC by Matrix Algebra}

The following discussion is given for completeness, not as a recommendation. The matrix method has gained some undeserved prominence, and this example is offered to provide a better insight into the method, to show that it is equivalent to alternatives, and to illustrate some deficiencies. I assume a basic knowledge of matrix algebra, and for more background, consult Vanclay (1994a) or any elementary text on matrix algebra.

Recall the basic elements of matrix multiplication, and observe that they can readily be employed to represent upgrowth and mortality illustrated in Figure 1:

$$
\left[\begin{array}{ll}
a & 0 \\
b & c
\end{array}\right] \cdot\left[\begin{array}{l}
x \\
y
\end{array}\right]=\left[\begin{array}{l}
a x+0 y \\
b x+c y
\end{array}\right]
$$

where $\mathrm{a}, \mathrm{b}$ and $\mathrm{c}$ are growth parameters and $\mathrm{x}$ and $\mathrm{y}$ describe the initial stand table. More specifically, notice that $\mathrm{b}$ represents upgrowth, that a represents the proportion of trees, and that $\mathrm{a}+\mathrm{b}$ corresponds to survival. Since there can be no upgrowth from the largest class, c corresponds to survival (i.e., 1-mortality).

Recall that in Figure 1, we assumed that $10 \%$ of trees would die, and that $25 \%$ of survivors would grow into the next class during a 20 -year period. Thus we can express this as:

$$
\left[\begin{array}{cccc}
.675 & 0 & 0 & 0 \\
.225 & .675 & 0 & 0 \\
0 & .225 & .675 & 0 \\
0 & 0 & .225 & .9
\end{array}\right]
$$

However, we have assumed that recruits will replace any upgrowth from the smallest size class, so that the first (top left) element of this matrix can be set to 1 to account for this assumption. The initial stand table can be represented as a vector (i.e., $[100,50,25,12.5]^{\prime}$ ), so that the first 20 years of growth can be expressed (with some rounding):

$$
\left[\begin{array}{cccc}
1 & 0 & 0 & 0 \\
225 & .675 & 0 & 0 \\
0 & .225 & .675 & 0 \\
0 & 0 & .225 & .9
\end{array}\right] \cdot\left[\begin{array}{c}
100 \\
50 \\
25 \\
12.5
\end{array}\right]=\left[\begin{array}{c}
100 \\
56.3 \\
28.2 \\
16.9
\end{array}\right]
$$

At this point, we wish to simulate a harvest, which simply means moving all the trees in the largest size class to a new element of the stand table. So we expand the matrix and vectors to make a fifth class (harvested), and build a matrix to effect the harvest:

$$
\left[\begin{array}{lllll}
1 & 0 & 0 & 0 & 0 \\
0 & 1 & 0 & 0 & 0 \\
0 & 0 & 1 & 0 & 0 \\
0 & 0 & 0 & 0 & 0 \\
0 & 0 & 0 & 1 & 1
\end{array}\right] \cdot\left[\begin{array}{ccccc}
1 & 0 & 0 & 0 & 0 \\
.225 & .675 & 0 & 0 & 0 \\
0 & .225 & .675 & 0 & 0 \\
0 & 0 & .225 & .9 & 0 \\
0 & 0 & 0 & 0 & 1
\end{array}\right] \cdot\left[\begin{array}{c}
100 \\
50 \\
25 \\
12.5 \\
0
\end{array}\right]=\left[\begin{array}{c}
100 \\
56.3 \\
28.2 \\
0 \\
16.9
\end{array}\right]
$$


The ones in the last (bottom right) element of both matrices simply means that the harvests will be summed over successive harvests rather than getting re-set to zero each time.

Now we wish to "grow" the stand a further 20 years to the end of the cutting cycle:

$$
\left[\begin{array}{ccccc}
1 & 0 & 0 & 0 & 0 \\
225 & .675 & 0 & 0 & 0 \\
0 & .225 & .675 & 0 & 0 \\
0 & 0 & .225 & .9 & 0 \\
0 & 0 & 0 & 0 & 1
\end{array}\right] \cdot\left[\begin{array}{lllll}
1 & 0 & 0 & 0 & 0 \\
0 & 1 & 0 & 0 & 0 \\
0 & 0 & 1 & 0 & 0 \\
0 & 0 & 0 & 0 & 0 \\
0 & 0 & 0 & 1 & 1
\end{array}\right] \cdot\left[\begin{array}{ccccc}
1 & 0 & 0 & 0 & 0 \\
.225 & .675 & 0 & 0 & 0 \\
0 & .225 & .675 & 0 & 0 \\
0 & 0 & .225 & .9 & 0 \\
0 & 0 & 0 & 0 & 1
\end{array}\right] .\left[\begin{array}{c}
100 \\
50 \\
25 \\
12.5 \\
0
\end{array}\right]
$$

and to repeat the procedure for 10 cutting cycles:

$$
\left[\left[\begin{array}{ccccc}
1 & 0 & 0 & 0 & 0 \\
225 & .675 & 0 & 0 & 0 \\
0 & .225 & .675 & 0 & 0 \\
0 & 0 & .225 & .9 & 0 \\
0 & 0 & 0 & 0 & 1
\end{array}\right] \cdot\left[\begin{array}{lllll}
1 & 0 & 0 & 0 & 0 \\
0 & 1 & 0 & 0 & 0 \\
0 & 0 & 1 & 0 & 0 \\
0 & 0 & 0 & 0 & 0 \\
0 & 0 & 0 & 1 & 1
\end{array}\right] \cdot\left[\begin{array}{ccccc}
1 & 0 & 0 & 0 & 0 \\
.225 & .675 & 0 & 0 & 0 \\
0 & .225 & .675 & 0 & 0 \\
0 & 0 & .225 & .9 & 0 \\
0 & 0 & 0 & 0 & 1
\end{array}\right]\right)^{10}\left[\begin{array}{c}
100 \\
50 \\
25 \\
12.5 \\
0
\end{array}\right]
$$

This calculation is equivalent to that illustrated in Figure 1, except that individual harvests will be revealed only at intermediate steps, and the final result will provide the total harvest over 10 cutting cycles.

It is possible to collapse these matrices into a single matrix, or into two matrices as was illustrated in the text (the two-matrix formulation is more transparent than the single-matrix version, as it has coefficients that can easily be interpreted in terms of the stated assumptions):

$$
\left[\left[\begin{array}{ccccc}
1 & 0 & 0 & 0 & 0 \\
225 & .675 & 0 & 0 & 0 \\
0 & .225 & .675 & 0 & 0 \\
0 & 0 & .225 & .9 & 0 \\
0 & 0 & 0 & 0 & 1
\end{array}\right] \cdot\left[\begin{array}{ccccc}
1 & 0 & 0 & 0 & 0 \\
225 & .675 & 0 & 0 & 0 \\
0 & .225 & .675 & 0 & 0 \\
0 & 0 & 0 & 0 & 0 \\
0 & 0 & .225 & .9 & 1
\end{array}\right]\right)^{10} \cdot\left[\begin{array}{c}
100 \\
50 \\
25 \\
12.5 \\
0
\end{array}\right]
$$

Clearly, this is a very simple illustration of the matrix method, and greater sophistication is possible, but the fundamental principles and limitations remain (Vanclay 1994a). 